Brief Report

\title{
Intranasal Rapamycin Rescues Mice from Staphylococcal Enterotoxin B-Induced Shock
}

\section{Teresa Krakauer * and Marilyn Buckley}

Integrated Toxicology Division, U.S. Army Medical Research Institute of Infectious Diseases, Fort Detrick, MD 21702, USA; E-Mail: marilyn.buckley@us.army.mil

* Author to whom correspondence should be addressed; E-Mail: Teresa.krakauer@amedd.army.mil; Tel.: +1-301-619-4733.

Received: 2 July 2012; in revised form: 6 August 2012 / Accepted: 13 August 2012 /

Published: 18 September 2012

\begin{abstract}
Staphylococcal enterotoxin B (SEB) and related exotoxins produced by Staphylococcus aureus are potent activators of the immune system and cause toxic shock in humans. Currently there is no effective treatment except for the use of intravenous immunoglobulins administered shortly after SEB exposure. Intranasal SEB induces long-lasting lung injury which requires prolonged drug treatment. We investigated the effects of rapamycin, an immunosuppressive drug used to prevent graft rejection, by intranasal administration in a lethal mouse model of SEB-induced shock. The results show that intranasal rapamycin alone delivered as late as $17 \mathrm{~h}$ after SEB protected $100 \%$ of mice from lethal shock. Additionally, rapamycin diminished the weight loss and temperature fluctuations elicited by SEB. Intranasal rapamycin attenuated lung MCP-1, IL-2, IL-6, and IFN $\gamma$ by $70 \%, 30 \%, 64 \%$, and $68 \%$ respectively. Furthermore, short courses (three doses) of rapamycin were sufficient to block SEB-induced shock. Intranasal rapamycin represents a novel use of an immunosuppressant targeting directly to site of toxin exposure, reducing dosages needed and allowing a wider therapeutic window.
\end{abstract}

Keywords: intranasal rapamycin; staphylococcal enterotoxin B; shock

\section{Introduction}

Staphylococcal enterotoxin B (SEB) and structurally related exotoxins are bacterial virulence factors that cause a variety of diseases in humans, ranging from food poisoning, autoimmune diseases, 
and toxic shock [1-7]. These toxins bind directly to the major histocompatibility complex (MHC) class II molecules on antigen-presenting cells and specific V $\beta$ regions of the T-cell receptors [8-12]. Staphylococcal exotoxins (SE) are called superantigens due to their ability to polyclonally activate $\mathrm{T}$ cells at picomolar concentrations $[7,10,13]$. Their interactions with cells of the immune system result in a massive release of proinflammatory cytokines and chemokines [5,7,14]. These proinflammatory mediators enhance leukocyte migration, promote tissue injury, and coagulation [15]. In particular, tumor necrosis factor $\alpha(\mathrm{TNF} \alpha)$, interleukin 1 (IL-1) and IFN $\gamma$, are pathogenic at high concentrations in vivo and are responsible for fever and toxic shock induced by SE [16-20].

In humans, toxic shock syndrome is characterized by fever, hypotension, desquamation of skin, and dysfunction of multiple organ systems $[1,4,6]$. Humans are very sensitive to SEB intoxication and low doses cause lethal shock, especially via the respiratory route [21]. There is currently no effective therapeutic for treating SEB-induced shock except for the use of intravenous immunoglobulins which must be administered close to the time of toxin exposure [22]. Various murine models were used to develop therapeutics to mitigate SEB-induced shock, although mice are poor responders to SEB due to low affinity of these toxins to mouse MHC class II [9,11]. The most common murine models used rely on the use of sensitizing agents such as D-galactosamine, actinomycin D, lipopolysaccharide (LPS), or viruses to amplify the responses to SEB in toxic shock models [23-25]. Transgenic mice expressing human MHC class II were found to be a better animal model for examining the biological effects of superantigens, as they respond to toxins due to the higher affinity binding of SEs to human MHC class II molecules [26,27]. An alternative murine model of toxic shock using two low doses of SEB without the use of confounding sensitizing agents was developed recently [28]. In this "SEB-only" toxic shock model, SEB was administered intranasally and another dose of SEB was strategically given $2 \mathrm{~h}$ later by intraperitoneal (i.p.) or intranasal (i.n.) routes to induce systemic and pulmonary inflammation with lethality as an endpoint.

We described in this study the effect of intranasal rapamycin, a FDA-approved immunosuppressant for kidney transplantation [29], in rescuing mice from SEB-induced shock. Rapamycin binds intracellularly to FK506-binding proteins, specifically FKBP12, the rapamycin-FKBP12 complex then binds to a distinct molecular target called mammalian target of rapamycin (mTOR) and this signaling pathway regulates metabolism as well as immune function [30]. Rapamycin suppresses $\mathrm{T}$ cell proliferation [30] and also upregulates the expansion of regulatory $\mathrm{T}$ cells [31]. Thus, rapamycin has effects on many types of effector T cells and is likely to be useful in mitigating SEB-activated immune responses.

\section{Results and Discussion}

\subsection{Therapeutic Window of Rapamycin Treatment}

We previously established that rapamycin was effective in attenuating the biological effects of SEB in vitro and that multiple dosing schedule of intraperitoneal rapamycin protected mice from SEB-induced shock [32]. Due to the potency of rapamycin by the i.p. route, we investigated if lower doses of rapamycin administered only by the intranasal route would be protective against SEB-induced toxic shock. We explored the therapeutic window of treatment by administrating rapamycin at increasing intervals after SEB exposure. Intranasal administration of rapamycin $(0.16 \mathrm{mg} / \mathrm{kg})$ at $5 \mathrm{~h}$ after SEB 
followed by the same dose i.n. at 24, 48, 72, $96 \mathrm{~h}$ (R5h5d) protected mice 100\% (Table 1). Only 22\% survival was recorded if intranasal rapamycin was delayed to $24 \mathrm{~h}$ after SEB (R245d). However, starting rapamycin at $5 \mathrm{~h}$ after SEB exposure but using one less dose was $100 \%$ effective (R5h4d). Importantly, low intranasal doses of rapamycin administered as late as $17 \mathrm{~h}$ after SEB exposure followed by doses at 23, $41 \mathrm{~h}$ was still $100 \%$ protective (R17h3d). The last dose at $41 \mathrm{~h}$ was necessary using this schedule of treatment, as eliminating this dose yielded only $70 \%$ survival. Kaplan Meier survival analysis (Figure 1) shows rapamycin extended survival times even in unprotected animals. Clinical signs of intoxication such as ruffled fur and lethargy observed with SEB-treated mice starting at $72 \mathrm{~h}$ were completely absent from the SEB plus rapamycin group.

Table 1. Protective effects of intranasal rapamycin.

\begin{tabular}{|c|c|}
\hline Toxin + rapamycin $(\mathrm{R})$ regiment $^{\mathrm{a}}$ & Live/Total $^{\mathrm{b}}$ \\
\hline SEB & $0 / 9$ \\
\hline $\mathrm{SEB}+\mathrm{R}$ at $5,24,48,72,96 \mathrm{~h}(\mathrm{R} 5 \mathrm{~h} 5 \mathrm{~d})$ & 9/9 \\
\hline $\mathrm{SEB}+\mathrm{R}$ at $24,30,48,72,96 \mathrm{~h}(\mathrm{R} 24 \mathrm{~h} 5 \mathrm{~d})$ & 2/9 \\
\hline SEB & $0 / 10$ \\
\hline $\mathrm{SEB}+\mathrm{R}$ at $5,24,48,72 \mathrm{~h}(\mathrm{R} 5 \mathrm{~h} 4 \mathrm{~d})$ & $10 / 10$ \\
\hline $\mathrm{SEB}+\mathrm{R}$ at $17,23,41 \mathrm{~h}(\mathrm{R} 17 \mathrm{~h} 3 \mathrm{~d})$ & $10 / 10$ \\
\hline $\mathrm{SEB}+\mathrm{R}$ at $17,23 \mathrm{~h}(\mathrm{R} 17 \mathrm{~h} 2 \mathrm{~d})$ & $7 / 10$ \\
\hline
\end{tabular}

${ }^{\mathrm{a}}$ Rapamycin $(0.16 \mathrm{mg} / \mathrm{kg})$ was administered i.n. at the specific time after SEB exposure as indicated. Bovine serum albumin controls ( $5 \mu \mathrm{g}$ i.n. plus $2 \mu \mathrm{g}$ i.p.) yielded no deaths $\left(n=10\right.$ animals per group). ${ }^{\mathrm{b}}$ Results obtained with rapamycin groups were statistically significant (except for the SEB + R24h5d group) from SEB groups $(p<0.02)$.

Figure 1. Survival analysis of Staphylococcal enterotoxin B (SEB)-exposed mice treated with intranasal rapamycin. Number of animals and schedule of treatment are identical to those presented in Table 1.

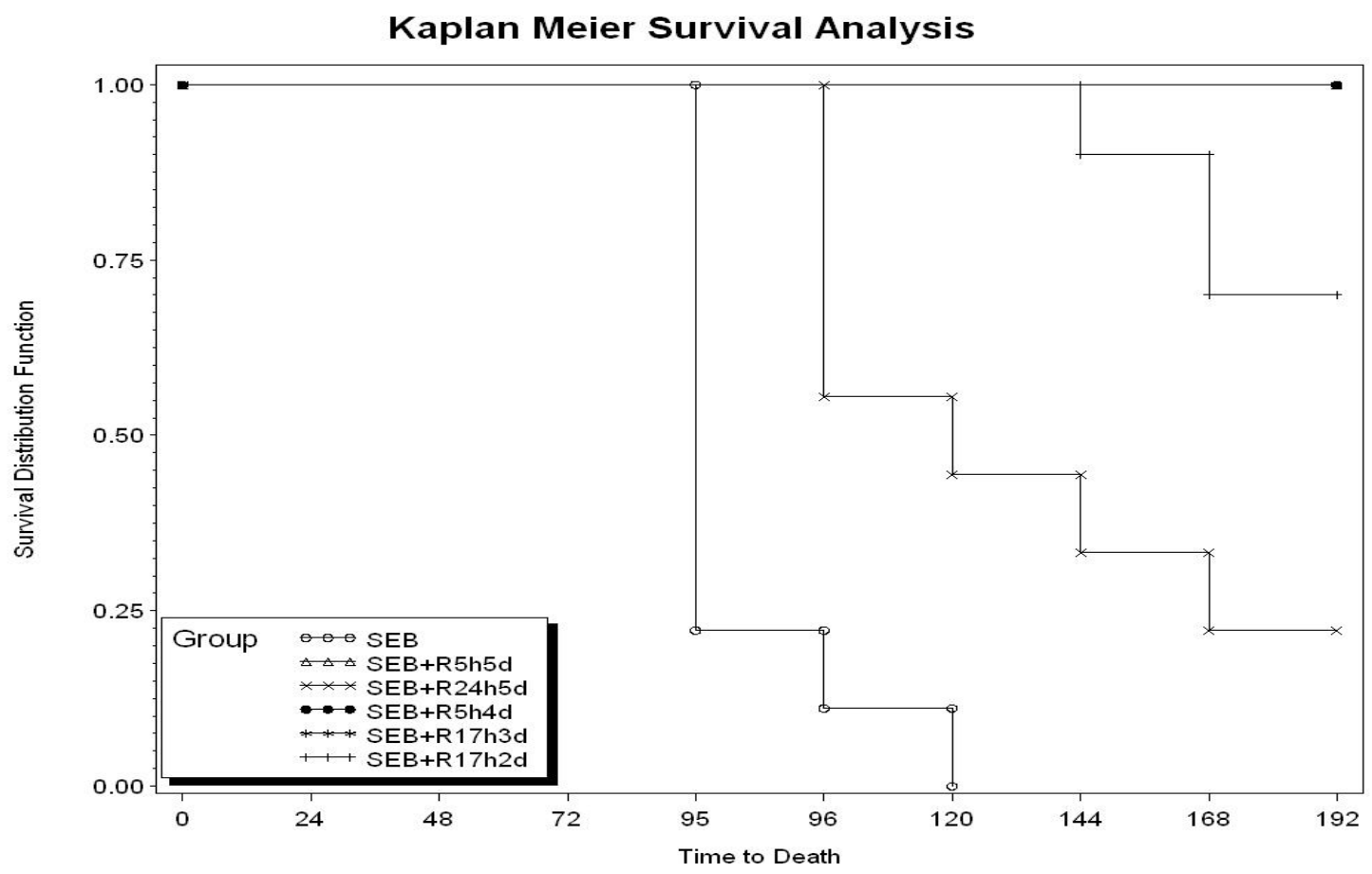




\subsection{Rapamycin Prevents Hyperthermia in SEB-Induced Shock Model}

Additional data were collected regarding temperature fluctuations in mice treated with SEB and those treated with SEB plus intranasal rapamycin given at various times after SEB (Figure 2). Mice given SEB experienced hypothermia starting at $48 \mathrm{~h}$. This hypothermic response, indicating systemic shock that mimicked those found in other murine models [26,33,34], was completely absent in rapamycin-treated SEB-exposed mice. Reducing the duration of treatment with rapamycin to $72 \mathrm{~h}$ also protected mice from hyperthermia if treatment was started at $5 \mathrm{~h}$ (SEB $+\mathrm{R} 5 \mathrm{~h} 4 \mathrm{~d})$. However, delaying treatment with rapamycin until $24 \mathrm{~h}$ resulted in shock like symptoms and hyperthermia (SEB + R24h5d). We progressively adjusted the time between the exposure of mice to SEB and rapamycin treatment to determine the maximum therapeutic window. A protective regimen of rapamycin starting at $17 \mathrm{~h}$ after SEB exposure followed by two other intranasal doses at 23 and $41 \mathrm{~h}$ also did not result in hypothermia. Clearly, rapamycin-treated and protected mice had minor temperature changes during the entire observation period.

Figure 2. Intranasal rapamycin attenuated the hypothermic response of mice treated with SEB. Body temperatures of mice $(n=9$ or $n=10)$ exposed to SEB and SEB plus rapamycin $(0.16 \mathrm{mg} / \mathrm{kg})$ at different time points after SEB exposure. Group identifiers are identical to those in Table 1. Points represent the means \pm SD for each group. Grey arrow indicates time of SEB exposure and black arrows represent time of rapamycin administration for the SEB $+\mathrm{R} 17 \mathrm{~h} 3 \mathrm{~d}$ group.

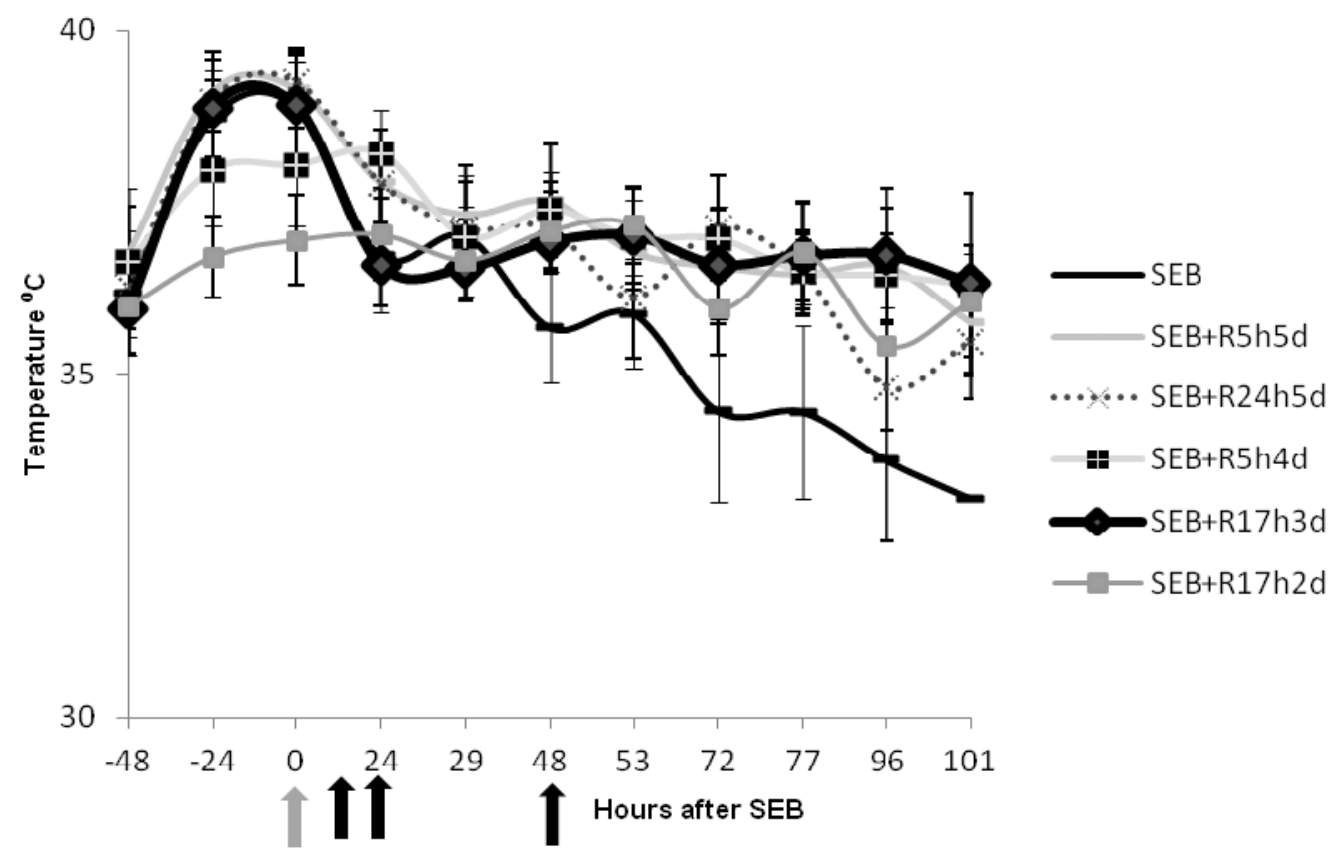

\subsection{Rapamycin Prevents Weight Loss in SEB-Induced Shock Model}

Weight loss is another prominent indicator of SEB-induced shock in other animal models of superantigen-induced disease [16]. We therefore examined the effect of rapamycin on the weight of animals after intranasal SEB. SEB-exposed mice experienced weight loss of $3 \%-7 \%$ at $53 \mathrm{~h}$ with drastic weight reduction over time. Most of the rapamycin-treated, SEB-exposed mice had $1 \%$ change 
in weight with some groups of mice gaining weight at later times (Figure 3). Mice receiving only two doses of rapamycin starting at $17 \mathrm{~h}$ (SEB $+\mathrm{R} 17 \mathrm{hd} 2)$ had 8\% weight loss and weight remained at this level after $53 \mathrm{~h}(70 \%$ survival). Protection against temperature and weight fluctuations essentially paralleled the lethality data.

Figure 3. Intranasal rapamycin prevented weight loss in mice treated with SEB. Weights of mice ( $n=9$ or $n=10)$ exposed to SEB and SEB plus rapamycin $(0.16 \mathrm{mg} / \mathrm{kg})$ at different time points after SEB exposure. Group identifiers are identical to those in Table 1. Points represent the average $\%$ weight change \pm SD for each group. Grey arrow indicates time of SEB exposure and black arrows represent time of rapamycin administration for the $\mathrm{SEB}+\mathrm{R} 17 \mathrm{~h} 3 \mathrm{~d}$ group.

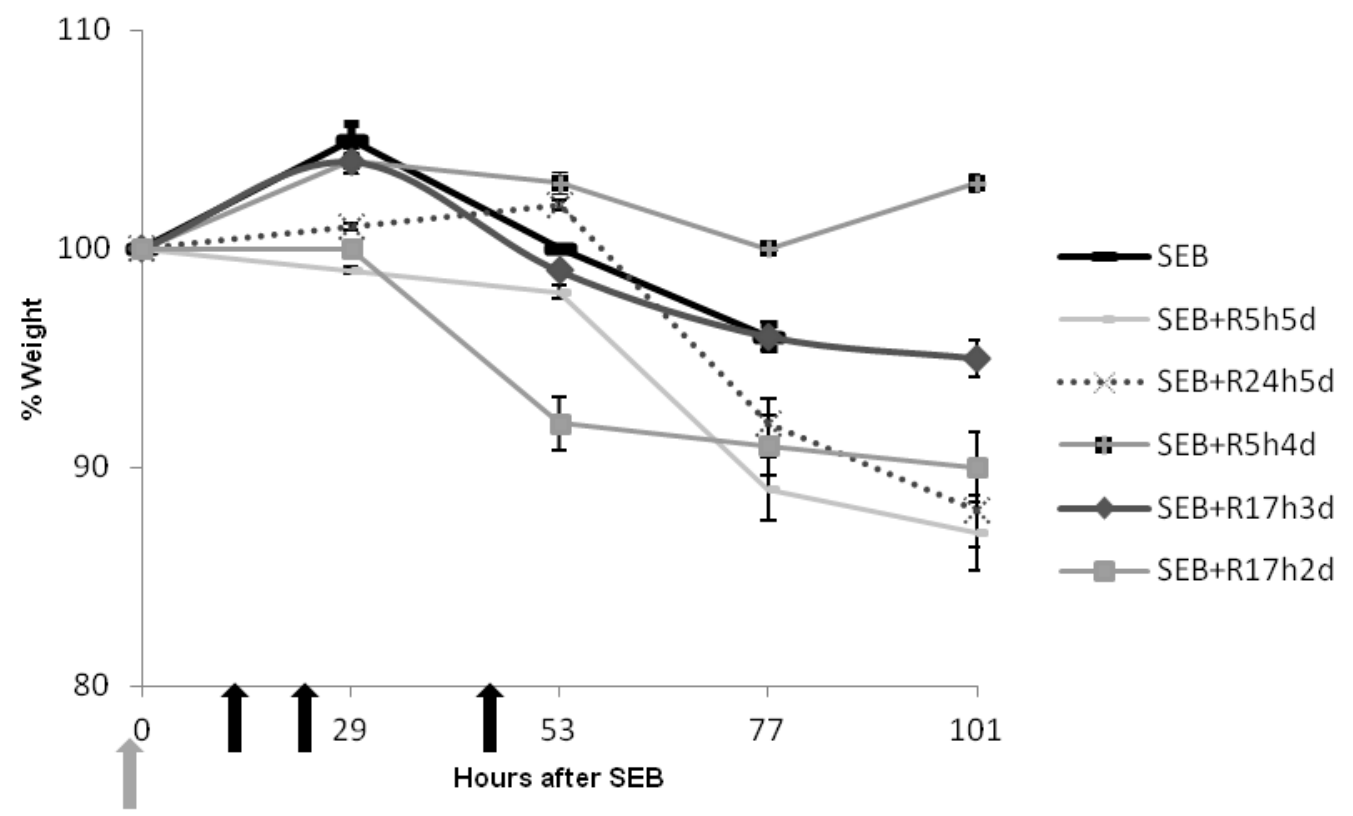

\subsection{Rapamycin Attenuates Pulmonary Mediators}

Proinflammatory cytokines mediate the lethal and pathological effects of SEB and monocyte chemoattractant protein (MCP-1), interleukin 2 (IL-2), IL-6 and gamma interferon (IFN $\gamma$ ) are critical mediators in various mouse models of SEB-induced shock [19,23,26,28,32]. We next examined the effect of intranasal rapamycin on these pulmonary mediators. Figure 4 shows that high levels of MCP-1, IL-2, IL-6, and IFN $\gamma$ were present in lung tissue at $42 \mathrm{~h}$ post-SEB treatment. In contrast, mice treated with rapamycin at $15 \mathrm{~h}$ followed by two additional doses at 21 and $39 \mathrm{~h}$ after SEB attenuated MCP-1, IL-2, IL-6, and IFN $\gamma$ by $70 \%, 30 \%, 64 \%$, and $68 \%$ respectively. These findings indicate a protective regimen of rapamycin is also effective in reducing the pulmonary mediators critical in initiating cell migration, cell activation, inflammation culminating in lung injury.

Bacterial superantigens cause toxic shock and contribute to septic complications during infection and only antibodies to superantigens and steroids had proven to be effective when administered early after exposure. The present study demonstrates for the first time that intranasal low dose rapamycin was $100 \%$ effective in protecting mice from SEB-mediated shock. Previous studies of drug treatment for SEB- and other superantigen-induced shock models indicate a very narrow therapeutic window of 
treatment $[19,20]$. This study indicates a much wider therapeutic window for rapamycin and that a new modality of using low doses of rapamycin even when administered $17 \mathrm{~h}$ after SEB was still protective $100 \%$ against mortality. Concomitantly, intranasal rapamycin treatment reduced temperature and weight fluctuations in SEB-treated mice.

Figure 4. Chemokine and cytokine assessment at $42 \mathrm{~h}$ in lungs of mice treated with intranasal rapamycin after SEB challenge. Values represent the mean $\pm \mathrm{SE}$ for five mice and results are statistically significant $(p<0.05)$ between SEB and SEB + rapamycin group.

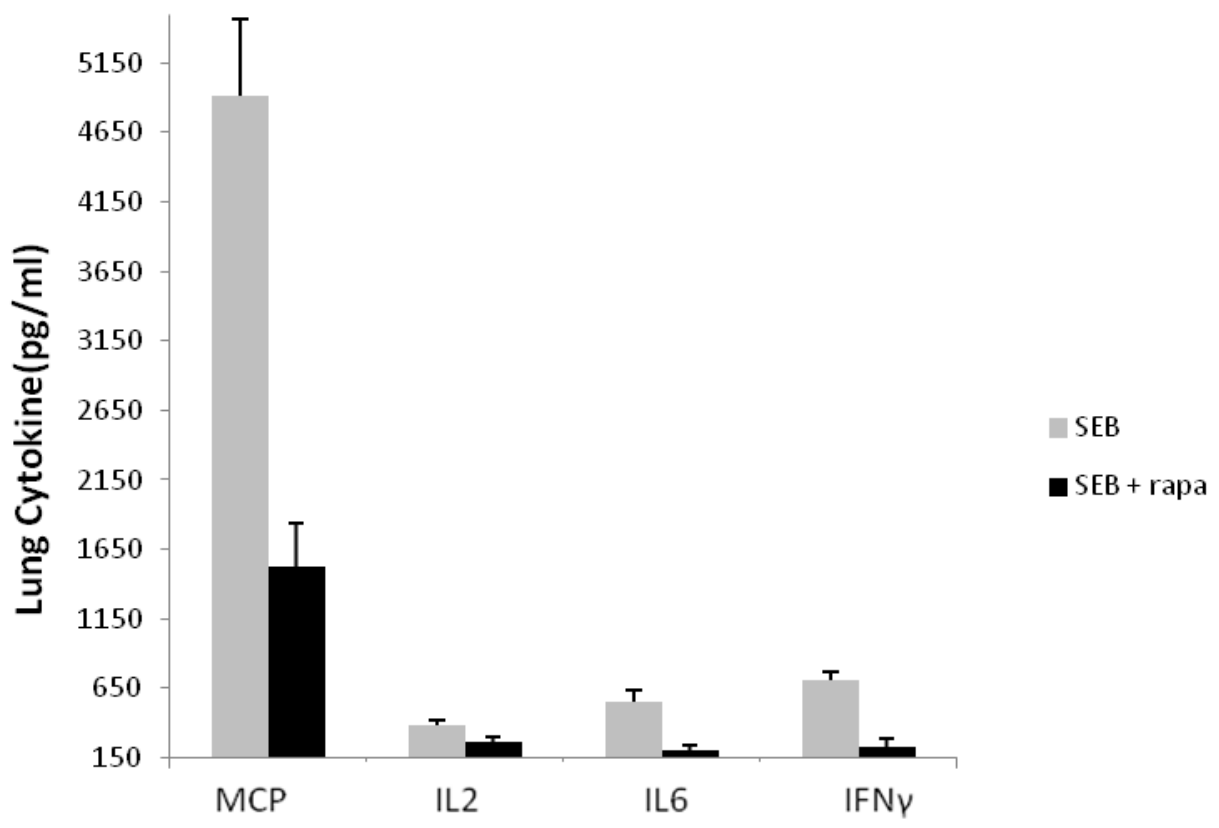

Excessive release of cytokines contributes to the pathophysiological process of toxic shock as proinflammatory cytokines and chemokines regulate leukocyte migration and promote tissue injury. We previously reported that IL-2 and MCP-1 play a central role in this intranasal model of SEB-induced toxicity and lung inflammation [28]. IFN $\gamma$, the prototypic $\mathrm{T}$ helper 1 type cytokine produced by activated $\mathrm{T}$ cells is a key inflammatory cytokine as it synergizes with other cytokines to promote injury in addition to its anti-viral and anti-proliferative effects. IFN $\gamma$ was also showed to affect metabolism as anti-IFN $\gamma$ prevented weight loss in a D-galctosamine-sensitized murine model of SEB-induced shock [35]. Importantly, these critical cytokines were elevated in lung tissue after SEB exposure and were effectively reduced in lungs with rapamycin treatment.

Based on the data presented, we propose that the mTOR signaling pathway plays an important role in the pathophysiology of SEB-mediated shock. The serine-threonine kinase, mTOR senses nutrient/growth factor inputs and cellular ATP levels via growth factor receptors and AMP-activated protein kinase, respectively [30]. In a separate pathway, IL-2 and IFN $\gamma$ receptor signaling activates phosphoinositide 3-kinase (PI3K) which acts upstream of mTOR and provides a critical link between cytokine receptor signaling and energy homeostasis. mTOR complex 1 (mTORC1), one of two key proteins of mTOR signaling is sensitive to rapamycin. Rapamycin acts by binding to FKBP12, an immunophilin, blocking mTOC1 activity and inhibiting cell cycle progression and protein synthesis. In this regard, it is interesting that FKBP12 is also found in abundance in neuronal cells and blocking 
FKBP12 was reported to reverse neuronal degeneration [36]. Bidirectional crosstalk between the neuroendocrine and the immune system is critical in the elimination of pathogens and proinflammatory cytokines are known to act on the hypothalamus to modulate neuronal pathways [37]. Future experiments should address if neuroimmunophilins are involved in the SEB-intoxication process.

\section{Experimental Section}

\subsection{Materials}

Purified SEB was obtained from Toxin Technology (Sarasota, FL, USA). The endotoxin content of these preparations was $<1 \mathrm{ng}$ of endotoxin/mg protein, as determined by the Limulus amoebocyte lysate assay (BioWhittaker, Walkersville, MD, USA). Rapamycin and other reagents were from Sigma (St. Louis, MO, USA).

\subsection{Mouse Model of SEB-Induced Shock}

Male $\mathrm{C} 3 \mathrm{H} / \mathrm{HeJ}$ mice (National Cancer Institute, Frederick, MD, USA), weighing $20 \mathrm{~g}$ each (7-10-weeks old), were housed in conventional microisolator cages. Sterile temperature/identification transponders (IPTT-300, Biomedic Data Systems, Seaford, DE, USA) were implanted subcutaneously into each animal 5-10 days before SEB and temperatures were monitored twice daily, between 8 and 9 a.m. and again between 3 and 4 p.m. A previous study with a murine LPS-potentiated SEB-induced shock model using telemetry to monitor core temperature indicated a good correlation between core and subcutaneous temperature changes [34]. Initial weight of animals was recorded 3-7 days before SEB exposure and weight changes were recorded once daily between 3 and 4 p.m. Temperature and weight were recorded at the same time of the day to avoid diurnal effects. SEB was administered i.n. $(50 \mu \mathrm{L}), 5 \mu \mathrm{g} /$ mouse with a micropipet and i.p. $(200 \mu \mathrm{L}), 2 \mu \mathrm{g} /$ mouse with a tuberculin syringe (26G-3/8-inch needle) between 8 and 9 a.m., immediately after the first temperature measurements of the day. All i.n. doses were administered to mice previously anesthetized with an intramuscular (i.m.)-injected mixture of ketamine $(2.4 \mathrm{mg} / \mathrm{kg})$, acepromazine $(0.024 \mathrm{mg} / \mathrm{kg})$, and xylazine $(0.27 \mathrm{mg} / \mathrm{kg})$. There were $2 \mathrm{~h}$ of elapsed time between the first i.n. dose and the second i.p. dose of SEB as this was the optimal time previously determined to cause toxic shock without the use of synergistic agents [28]. Mice exposed to both doses of SEB were hypothermic starting between $48 \mathrm{~h}-72 \mathrm{~h}$ and lethal endpoints were recorded up to $192 \mathrm{~h}$ after the first toxin dose. Controls consisted of C3H/HeJ mice given two doses of either bovine serum albumin (BSA, Sigma Chemical Corp.) or saline $2 \mathrm{~h}$ apart, similar to those of SEB-exposed mice (i.e., by i.n. and i.p.). For therapeutic investigations, mice ( $n=9$ or $n=10$ mice per group as specified in figures) were given rapamycin i.n. at specific times after intranasal SEB exposure as described for each series of experiment. Intranasal rapamycin $(0.16 \mathrm{mg} / \mathrm{kg}$ of body weight) in sterile saline was administered with a micropipette at the designated time points. Animals were monitored twice daily for illness and moribund condition for $96 \mathrm{~h}$ and as needed. Temperature and weight changes were measured daily up to 96-120 h. Temperature data were calculated as the mean temperature reading \pm standard deviation of each group $(n=9$ or $n=10$ mice per group). Survival rates were recorded at $192 \mathrm{~h}$. 
Research was conducted under an IACUC approved protocol in compliance with the Animal Welfare Act and other Federal statutes and regulations relating to animals and experiments involving animals and adheres to principles stated in the Guide for the Care and Use of Laboratory Animals, National Research Council, 1996. The facility where this research was conducted is fully accredited by the Association for Assessment and Accreditation of Laboratory Animal Care International.

\subsection{Cytokine and Chemokine Assays}

IL-2, IL-6, and MCP-1 were assayed by ELISA using matched pairs of specific anti-mouse antibodies as described previously [28,32]. Matched pairs of anti-mouse antibodies for cytokines and chemokines, and protein standards were purchased from BD Pharmingen (San Diego, CA, USA) and used in ELISA assays of cytokines according to manufacturer's protocols. IFN $\gamma$ was determined using Quantikine ELISA kit from R\&D Systems (Minneapolis, MN, USA) as described in manufacturer's instruction manual.

Whole lungs ( $n=5$ mice per group) were excised from euthanized animals at $42 \mathrm{~h}$ post-SEB challenge, weighed, and frozen at $-70{ }^{\circ} \mathrm{C}$. Rapamycin treated mice received rapamycin $(0.16 \mathrm{mg} / \mathrm{kg})$ intranasally at $15 \mathrm{~h}$ after SEB followed by intranasal doses at 21 and $39 \mathrm{~h}$. Immediately before cytokine assays, lungs were thawed and homogenized for $30 \mathrm{~min}$ at $4{ }^{\circ} \mathrm{C}$ in lysis buffer (Cell Signaling Technology, Danvers, MA, USA) to a $6.9 \mathrm{mg} / \mathrm{mL}$ concentration with Complete protease inhibitor (Roche Applied Science, Indianapolis, IN, USA). Homogenates were then centrifuged at $500 \times g$ for $10 \mathrm{~min}$, supernatants harvested, and the latter filtered through a $0.45 \mu \mathrm{M}$ membrane (Millipore, Bedford, MA, USA). Bicinchoninic acid assay (Pierce, Rockford, IL, USA) was used to estimate protein concentrations in lung homogenates and results of lung homogenates were normalized based on protein concentration.

\subsection{Statistical Analysis}

Data were expressed as the mean $\pm \mathrm{SE}$ and were analyzed for significant difference by Student's $t$-test. Statistical comparisons of survival data were performed by Fisher's exact test with Stata software (Stata Corp., College Station, TX, USA). Differences were considered significant if $P$ was $<0.05$.

\section{Conclusions}

The novel application of intranasal rapamycin represents a new treatment modality for SEB introduced via the respiratory route. This concept of directing drug delivery to site of inflammation and injury has proven to be fast and effective as shown in the use of steroid for treating asthma. In applying this concept, we found low doses of intranasal rapamycin to be effective when administered as late as $17 \mathrm{~h}$ after SEB. In comparison, our previous study with the steroid dexamethasone in the same SEB-induced shock model showed that dexamethasone was effective only if administered $5 \mathrm{~h}$ after SEB and was not protective when given at $17 \mathrm{~h}$ [32]. Furthermore, long courses of dexamethasone up to $96 \mathrm{~h}$ were required to prevent shock whereas a much shorter duration of treatment with intranasal rapamycin $(41 \mathrm{~h})$ was sufficient to prevent SEB-induced shock. The shorter duration of treatment and delayed start of treatment after SEB exposure with rapamycin is of obvious advantage as currently the 
only effective treatment with anti-toxin/superantigen or steroid can prevent shock only if treatment is administered early post-SEB exposure.

\section{Acknowledgments}

We thank the Defense Threat Reduction Agency for generous support.

\section{Conflict of Interest}

The authors declare no conflict of interest. The views expressed in this publication are those of the author and do not reflect the official policy or position of the Department of the Army, the Department of Defense, or the U.S. Government.

\section{References}

1. Chesney, P.J.; Davis, J.P.; Purday, W.K.; Wand, P.J.; Chesney, R.W. Clinical manifestations of toxic shock syndrome. J. Am. Med. Assoc. 1981, 246, 741-748.

2. Holmberg, S.D.; Blake, P.A. Staphylococcal food poisoning in the United States. New facts and old misconceptions. JAMA 1984, 251, 487-489.

3. Wieneke, A.; Roberts, D.; Gilbert, R.J. Staphyloccal food poisoning in the United Kingdom. Epidemiol. Infect. 1990, 110, 519-531.

4. Kotzin, B.L.; Leung, D.Y.M.; Kappler, J.; Marrack, P.A. Superantigens and their potential role in human disease. Adv. Immunol. 1993, 54, 99-166.

5. McCormick, J.K.; Yarwood, J.M.; Schlievert, P.M. Toxic shock syndrome and bacterial superantigens: an update. Ann. Rev. Microbiol. 2001, 55, 77-104.

6. Stevens, D.L. The toxic shock syndromes. Infect. Dis. Clin. North Am. 1996, 10, 727-746.

7. Proft, T.; Fraser, J.D. Bacterial superantigens. Clin. Exp. Immunol. 2003, 133, 299-306.

8. Choi, Y.; Kotzin, B.; Hernon, L.; Callahan, J.; Marrack, P.; Kappler, J. Interaction of Staphyloccocus aureus toxin "superantigens" with human T cells. Proc. Natl. Acad. Sci. USA 1989, 86, 8941-8945.

9. Fleischer, B.; Schrezenmeier, H.; Conradt, P. T-lymphocyte activation by staphylococcal enterotoxins: Role of class II molecules and T cell surface structures. Cell. Immunol. 1989, 120, 92-101.

10. Marrack, P.; Kappler, J. The staphylococcal enterotoxins and their relatives. Science 1990, 248, 705-709.

11. Mollick, J.A.; Chintagumpala, M.; Cook, R.G.; Rich, R.R. Staphylococcal exotoxin activation of $\mathrm{T}$ cells. Role of exotoxin-MHC class II binding affinity and class II isotype. J. Immunol. 1991, 146, 463-468.

12. Scholl, P.; Diez, A.; Mourad, W.; Parsonnet, J.; Geha, R.S.; Chatila, T. Toxic shock syndrome toxin-1 binds to major histocompatibility complex class II molecules. Proc. Natl. Acad. Sci. USA 1989, $86,4210-4214$.

13. Fraser, J.D.; Proft, T. The bacterial superantigens and superantigen-like proteins. Immunol. Rev. 2008, 225, 226-243. 
14. Krakauer, T. Therapeutic down-modulators of staphylococcal superantigen-induced inflammation and toxic shock. Toxins 2010, 2, 1963-1983.

15. Krakauer, T.; Vilcek, J.; Oppenheim, J.J. TNF family cytokines, chemokines and other pro- or anti-inflammatory cytokines. In Fundamental Immunology, 4th ed.; Paul, W.E., Ed.; Lippincott Williams \& Wilkins: Philadelphia, PA, USA, 1999; pp. 783-811.

16. Miethke, T.; Wahl, C.; Heeg, K.; Echtenacher, B.; Krammer, P.H.; Wagner, H. T cell-mediated lethal shock triggered in mice by the superantigen SEB: Critical role of TNF. J. Exp. Med. 1992, 175, 91-98.

17. Stiles, B.G.; Bavari, S.; Krakauer, T.; Ulrich, R.G. Toxicity of staphylococcal enterotoxins potentiated by lipopolysaccharide: Major histocompatibility complex class II molecule dependency and cytokine release. Infect. Immun. 1993, 61, 5333-5338.

18. Blank, C.; Luz, A.; Bendigs, S.; Erdmann, A.; Wagner, H.; Heeg, K. Superantigen and endotoxin synergize in the induction of lethal shock. Eur. J. Immunol. 1997, 27, 825-833.

19. Arad, G.; Levy, R.; Hillman, D.; Kaempfer, R. Superantigen antagonist protects against lethal shock and defines a new domain for T-cell activation. Nat. Med. 2000, 6,414-421.

20. Visvanathan, K.; Charles, A.; Bannan, J.; Pugach, P.; Kashfi, K.; Zabriskie, J.B. Inhibition of bacterial superantigens by peptides and antibodies. Infect. Immun. 2001, 69, 875-884.

21. Madsen, J.M. Toxins as weapons of mass destruction. A comparison and contrast with biological-warfare and chemical-warfare agents. Clin. Lab. Med. 2001, 21, 593-605.

22. Darenberg, J.; Soderquist, B.; Normark, B.H.; Norrby-Tegland, A. Differences in potency of intravenous polyspecific immunoglobin $\mathrm{G}$ against streptoccocal and staphyloccocal superantigen: implications for therapy of toxic shock syndrome. Clin. Infect. Dis. 2004, 38, 836-842.

23. Nagaki, M.; Muto, Y.; Ohnishi, H.; Yasuda, S.; Sano, K.; Naito, T.; Maeda, T.; Yamada, T.; Moriwaki, H. Hepatic injury and lethal shock in galactosamine-sensitized mice induced by the superantigen staphylococcal enterotoxin B. Gastroenterology 1994, 106, 450-458.

24. Chen, J.Y.; Qiao, Y.; Komisar, J.L.; Bazem, W.B.; Hsu, I.C.; Tseng, J. Increased susceptibility to staphylococcal enterotoxin B intoxication in mice primed with actinomycin D. Infect. Immun. 1994, 62, 4626-4631.

25. Sarwar, S.R.; Blackman, M.A.; Doherty, P.C. Superantigen shock in mice with an inapparent viral infection. J. Infect. Dis. 1994, 170, 1189-1194.

26. Roy, C.J.; Warfield, K.L.; Welcher, B.C.; Gonzales, R.F.; Larsen, T.; Hanson, J.; David, C.S.; Krakauer, T.; Bavari, S. Human leukocyte antigen-DQ8 transgenic mice: a model to examine the toxicity of aerosolized staphylococcal enterotoxin B. Infect. Immun. 2005, 73, 2452-2460.

27. Yeung, R.S.; Penninger, J.M.; Kundig, T.; Khoo, W.; Ohashi, P.S.; Kroemer, G.; Mak, T.W. Human CD4 and human major histocompatibility complex class II (DQ6) transgenic mice: Supersensitivity to superantigen-induced septic shock. Eur. J. Immunol. 1996, 26, 1074-1082.

28. Huzella, L.M.; Buckley, M.J.; Alves, D.A.; Stiles, B.G.; Krakauer, T. Central roles for IL-2 and MCP-1 following intranasal exposure to SEB: A new mouse model. Res. Vet. Sci. 2009, 86, 241-247.

29. Flechner, S.M. Sirolimus in kidney transplantation indications and practical guidelines: Denovo sirolimus-based therapy without calcineurin inhibitors. Transplantation 2009, 87, S1-S6.

30. Thomson, A.W.; Turnquist, H.R.; Raimondi, G. Immunoregulatory functions of mTOR inhibition. Nat. Rev. Immunol. 2009, 9, 324-337. 
31. Coenen, J.J.; Koenen, H.J.; van Rijssen, E.; Hilbrands, L.B.; Joosten, I. Rapamycin, and not cyclosporin A, preserves the highly suppressive $\mathrm{CD} 27^{+}$subset of human $\mathrm{CD} 4^{+} \mathrm{CD} 25^{+}$regulatory $\mathrm{T}$ cells. Blood 2006, 107, 1018-1023.

32. Krakauer, T.; Buckley, M.; Issaq, H.J.; Fox, S.D. Rapamycin protects mice from staphylococcal enterotoxin B-induced toxic shock and blocks cytokine release in vitro and in vivo. Antimicrob. Agents Chemother. 2010, 54, 1125-1131.

33. Stiles, B.G.; Campbell, Y.G.; Castle, R.M.; Grove, S.A. Correlation of temperature and toxicity in murine studies of staphylococcal enterotoxins and toxic shock syndrome toxin 1. Infect. Immun. 1999, 67, 1521-1525.

34. Vlach, K.D.; Boles, J.W.; Stiles, B.G. Telemetric evaluation of body temperature and physical activity as predictors of mortality in a murine model of staphylococcal enterotoxic shock. Comp. Med. 2000, 50, 160-166.

35. Matthys, P.; Mitera, T.; Heremans, H.; Van Damme, J.; Billiau, A. Anti-gamma interferon and anti-interleukin-6 antibodies affect staphylococcal enterotoxin B-induced weight loss, hypoglycemia, and cytokine release in D-galctosamine-sensitized and unsensitized mice. Infect. Immun. 1995, 63, 1158-1164.

36. Nilsson, A.; Sköld, K.; Sjögren, B.; Svensson, M.; Pierson, J.; Zhang, X.; Caprioli, R.M.; Buijs, J.; Persson, B.; Svenningsson, P.; et al. Increased striatal mRNA and protein levels of the immunophilin FKBP-12 in experimental Parkinson's disease and identification of FKBP-12-binding proteins. J. Proteome Res. 2007, 6, 3952-3961.

37. Sternberg, E.M. Neural regulation of innate immunity: A coordinated nonspecific host response to pathogens. Nat. Rev. Immunol. 2006, 6, 318-328.

(C) 2012 by the authors; licensee MDPI, Basel, Switzerland. This article is an open access article distributed under the terms and conditions of the Creative Commons Attribution license (http://creativecommons.org/licenses/by/3.0/). 